\title{
Pleno emprego no Brasil: interpretando os conceitos e indicadores
}

Anita Kon*

Resumo: Tendo em vista o debate recente sobre a proximidade do pleno emprego no mercado de trabalho brasileiro, o artigo visa analisar alguns conceitos e indicadores utilizados para a análise deste mercado, partindo da hipótese de que os indicadores utilizados para a análise das taxas de desemprego do país mascaram a percepção da real situação do mercado de trabalho e levam a discussões não pertinentes sobre esta perspectiva. O trabalho analisa primeiramente os conceitos teóricos e empíricos sobre pleno emprego, como base para o entendimento do debate. Bem como a interpretação dos indicadores utilizados no país e internacionalmente para a determinação da taxa de desemprego. Finalmente avalia a aplicação destes conceitos e indicadores para a situação brasileira.

Palavras-chave: Desemprego; Emprego; Indicadores de trabalho; Políticas públicas; Brasil.

Classificação JEL: J01; J08; J64.

\footnotetext{
"Doutora em Economia pela Universidade de São Paulo (USP). Professora titular de Economia e coordenadora do Grupo de Pesquisas em Economia Industrial, Trabalho e Tecnologia do Programa de Estudos Pós-Graduados em Economia Política da da Pontifícia Universidade Católica (PUC)/SP. Endereço eletrônico: akon@terra.com.br.
} 


\section{Introdução}

O emprego e o rendimento real do trabalho no Brasil vêm crescendo tanto de forma quantitativa como qualitativa desde 2010, e dessa maneira observa-se uma melhora no padrão de crescimento do mercado de trabalho do país. As baixas taxas de desemprego que vêm sendo constatadas levaram alguns economistas a anunciarem a proximidade do pleno emprego no país. No entanto, outros pesquisadores consideram que as condições do mercado de trabalho ainda apresentam precariedades que afastam o pleno emprego dos horizontes prováveis para os próximos anos.

O debate está formado e argumentos favoráveis à perspectiva de pleno emprego apontam para o fato de que existe a oferta de postos de trabalho qualificado nas empresas, que não têm condições de serem preenchidos pela mão de obra brasileira, que vem incentivando a importação de trabalhadores especializados pelas empresas e, por outro lado, está aumentando a imigração de pessoas vindas de outros países em busca de melhores condições de trabalho. Existem analistas econômicos que acreditam que qualquer pessoa que esteja disposta a trabalhar no Brasil encontra uma ocupação.

A fragilidade destes argumentos é patente quando são analisadas empiricamente algumas características estruturais da qualidade das ocupações encontradas. A evolução e a distribuição dos rendimentos médios reais dos trabalhadores mostram que, embora crescentes, as remunerações de um contingente considerável de trabalhadores ainda se situam em níveis aquém de satisfatórios e condizentes com o melhor aproveitamento de sua potencial capacidade enquanto força de trabalho.

O objetivo deste artigo é analisar alguns conceitos e indicadores utilizados para a análise do mercado de trabalho brasileiro, partindo da hipótese de que os indicadores utilizados para a análise das taxas de desemprego do país mascaram a percepção da real situação do mercado de trabalho e levam a discussões viesadas sobre a perspectiva de proximidade do pleno emprego. A próxima seção analisa os conceitos teóricos e empíricos de pleno emprego, como base para o entendimento do debate e visa a interpretação dos indicadores utilizados para a determinação da situação de emprego no país e internacionalmente. A última seção avalia a aplicação destes conceitos e indicadores para a situação brasileira. 


\section{Os conceito em discussão: pleno emprego, desemprego ou desocupação?}

\subsection{Dois aspectos da discussão}

Desde meados do ano de 2010, a economia brasileira iniciou uma fase de recuperação das perdas de empregos verificadas no ano anterior, devidas aos impactos da crise financeira internacional. Em dezembro daquele ano, a taxa de desocupação divulgada pelo IBGE se situou no patamar de 5,3\% da PEA, fechando o ano com uma média de 6,7\%, consideravelmente inferior à média histórica anterior. A continuidade da diminuição gradativa das taxas em 2011, quando a média anual atingiu $6 \%$ e no mês de dezembro foi registrado o nível de 4,7\%, o menor indicador desde 2002 - ano em que as estatísticas de emprego do IBGE haviam sofrido uma reformulação metodológica - levou os economistas à discussão sobre a possibilidade do país estar muito perto do pleno emprego.

O forte ritmo de crescimento da economia nos últimos meses e o desempenho vigoroso do mercado de trabalho no Brasil, com a consequente redução do nível de desemprego, deve alçar o país a um cenário de pleno emprego. Segundo especialistas ouvidos, esse quadro está próximo de se concretizar. Com uma taxa de desemprego na faixa entre $5 \%$ e $6 \%$ esse cenário pode se confirmar, afirmam os analistas, entre o fim de 2010 e o primeiro semestre de 2011 (Caldeira, 2010).

O debate prossegue na literatura e na mídia com divergências consideráveis, com uma extensa variedade de argumentos favoráveis ou contrários à ideia de proximidade do pleno emprego. Algumas análises divulgadas pela mídia e também encontradas na literatura chegam a elaborar estimativas sobre o futuro da economia, utilizando modelos macroeconômicos tendo como base a hipótese do pleno emprego no país. Dois aspectos devem ser discutidos neste debate: a) o conceito de pleno emprego utilizado como base e as implicações para a economia da obtenção deste nível no país; e b) o indicador utilizado para a aferição do pleno emprego e sua adequação ao cenário do mercado de trabalho brasileiro.

\subsubsection{O significado do pleno emprego}

De um modo geral, pleno emprego pode significar que em determinado momento a população economicamente ativa realiza o volume de atividade máxima que é capaz de realizar e pode dizer-se que o pleno emprego se traduz numa situação em que todo o indivíduo que se apresenta no mercado de trabalho a procura de ocupação a encontra. O conceito de pleno emprego, em economia, tem 
como base uma situação em que não existe qualquer forma de desperdício, seja do capital ou do trabalho. O pleno emprego significa a utilização da capacidade máxima de produção de uma sociedade e, evidentemente, deve ser utilizada para elevar a qualidade de vida da população.

O conceito de pleno emprego teoricamente pode ser abordado quer com base na análise neoclássica, quer na keynesiana e ainda sob o ponto de vista da conceituação mais atualizada definida por vários países, sob a égide da Organização Internacional do Trabalho (Missio; Oreiro, 2006). Para os neoclássicos, o conceito de pleno emprego, em economia, tem como base o estado de equilíbrio entre a oferta e a demanda dos fatores de produção, com capacidade máxima de produção da sociedade instalada. Nesta situação não existe desperdício, em qualquer de suas formas, nem do capital e nem do trabalho, e como a oferta de trabalho era igual à demanda de trabalho, no equilíbrio não existe o fenômeno do desemprego (Pigou, 1968). Para os neoclássicos, só existiam dois tipos de desemprego: o "friccional" e o "voluntário", em que o volume de emprego é determinado pela oferta e demanda por trabalho a um salário de equilíbrio. O desemprego friccional ou natural ocorre em um período de tempo em que um ou mais indivíduos se desempregam de um trabalho para procurar outro, ou quando o trabalhador está em um período de transição de um trabalho para outro. Portanto, resulta da mobilidade da mão de obra. De outro lado, o desemprego voluntário designa a condição do trabalhador que não quer trabalhar a preços de mercado, ou seja, prefere não trabalhar do que receber o salário que lhe é oferecido no mercado ou está mudando de emprego.

Keynes, por sua vez, tentando entender a situação de crise econômica iniciada no final da década de 1920, questiona o fato de que esta teoria não explica o chamado desemprego involuntário, quando pessoas dispostas a trabalhar pelo salário de equilíbrio não encontram emprego. Para o autor, o ciclo econômico não é autoregulado como salientam os neoclássicos, uma vez que é determinado pelo "espírito animal" (animal spirit no original em inglês) dos empresários. Conclui que os salários não são os determinantes do emprego e que a rigidez dos salários não pode ser a responsável pelo desemprego involuntário, assim como a flexibilidade dos mesmos não garante a automaticidade da economia à posição de pleno emprego, o que quer dizer que a posição "normal" de uma economia capitalista corresponde ao ponto em que prevalece o equilíbrio com desemprego involuntário (Keynes, 1983, cap. 19). Dessa forma, considera a incapacidade do sistema capitalista conseguir empregar todos os que querem trabalhar, pois pode acontecer situações na economia em que há um excesso de poupança, em relação ao investimento, e consequentemente a demanda efetiva se mantem abaixo da oferta, tendo como resultado uma situação de redução do emprego até um ponto de equilíbrio em que a poupança e o investimento se igualem. 
Nesta situação de equilíbrio pode resultar a ocorrência de desemprego involuntário em economias avançadas (onde a quantidade de capital acumulado seja grande e sua produtividade seja pequena). Keynes prossegue com a ideia de que para a obtenção do pleno emprego, nestas condições, o Estado deveria intervir imprimindo moeda e aumentando a demanda efetiva através de déficits governamentais. Sua conclusão lógica era de que quanto maior fosse a produção da economia maior seria o volume de emprego demandado e, portanto, o volume de emprego oferecido num país dependia do volume de sua produção que é determinada pela demanda efetiva.

Para a Organização Internacional do Trabalho - OIT (1999) o pleno emprego é fundamental para a erradicação da pobreza e da fome. A população tem direito ao pleno emprego e cabe à sociedade estabelecer as leis e as normas que possibilitem a utilização integral da oferta de trabalho, desde que o pleno emprego é uma condição necessária para a restauração da dignidade dos trabalhadores e uma condição essencial para a estabilidade e o progresso da sociedade. No entanto, o pleno emprego deve vir acompanhado da noção de trabalho decente. O conceito de trabalho decente, introduzido em 1999 pela OIT, sintetiza as aspirações de todos os trabalhadores no que diz respeito à consecução de igualdade de acesso ao trabalho produtivo, em condições de liberdade, igualdade, segurança e dignidade.

O conceito reúne uma série de recomendações anteriores da OIT, buscando agregar dentro de um quadro único um conceito universal e aplicável a todos os trabalhadores. Abarca todas as modalidades de trabalho, tanto trabalho com carteira assinada, o autônomo, o trabalho na agricultura familiar e o autoemprego, incluindo o trabalho produtivo e reprodutivo. Nesse sentido, visando a melhor das condições de vida dos indivíduos, implica na existência de: (i) oportunidades para encontrar um emprego produtivo com rendimento justo, que garanta aos trabalhadores e suas famílias desfrutar uma qualidade de vida decente; (ii) liberdade para a escolha do trabalho e a livre participação em atividades sindicais; (iii) condições de tratamento justo aos trabalhadores, sem discriminação de modo a que sejam capazes de conciliar trabalho e responsabilidades familiares; (iv) condições de segurança para proteger a saúde dos trabalhadores e proporcionar-lhes a proteção social adequada; (v) condições de dignidade humana para que todos os trabalhadores sejam tratados com respeito e possam participar na tomada de decisão sobre suas condições de trabalho (OIT, 1999).

Como salienta ainda a OIT, existem duas formas de entender o mercado de trabalho, seja através da abordagem macroeconômica, ou da microeconômica. A abordagem macroeconômica examina de forma agregada as inter-relações entre o mercado de trabalho e outros mercados de produtos, monetário e o de 
comércio externo, investigando como estas interações influenciam as variáveis agregadas de emprego e rendimento nacional. É nesse sentido que o pleno emprego, enquanto parâmetro do agregado, tem sido mensurado e apontado como próximo de ser alcançado nas condições conjunturais brasileiras nos debates sobre o tema.

A abordagem microeconômica, por sua vez, foca no papel dos indivíduos, agregadas famílias, indivíduos e firmas, no mercado de trabalho. Os resultados destas questões microeconômicas afetam as questões macroeconômicas e por elas são afetadas, e a unidade destas duas visões é que irá explicar o significado da situação do pleno emprego em um dado momento de uma economia (OIT, 2011, p. 130).

Dessa maneira, algumas questões de políticas públicas contemporâneas requerem um tratamento especial através da visão microeconômica da macroeconomia. Tão relevante quanto definir o conceito de pleno emprego a ser tomado como base, é entender o que representa o pleno emprego para a economia. Se o pressuposto de que o pleno emprego é uma condição de aproveitamento completo da mão de obra disponível, é necessário observar que ainda que tenha atingido os parâmetros de pleno emprego, pode não haver um aproveitamento do potencial de trabalho. Este potencial pressupõe o pleno exercício das aptidões dos indivíduos, seja obtido através da educação geral ou da formação especializada ou do conhecimento tácito no exercício profissional, de modo a tornar cada indivíduo apto a produzir o maio valor adicionado possível a partir de sua capacidade e em contraponto usufruir o rendimento condizente.

A avaliação dos efeitos do pleno emprego em uma sociedade diz respeito também à verificação das questões estruturais sobre a qualidade do trabalho da população ocupada, de possibilidades de desenvolvimento profissional e de criação de condições favoráveis à mobilidade profissional e geográfica. A população ativa do Brasil inclui em proporção inferior indivíduos alocados em situações favoráveis de trabalho e remuneração e protegidos por contratos registrados do que a proporção de indivíduos em condições insatisfatórias de trabalho e de baixa remuneração. Trabalho precário e diferenças regionais impedem o Brasil de ser considerado um país com pleno emprego no sentido de possibilidade de elevação do nível de bem-estar da população.

\subsubsection{A interpretação dos indicadores utilizados}

As discussões sobre o pleno emprego no Brasil tem como base de informações a Pesquisa Mensal de Emprego (IBGE, 2007), cuja metodologia de mensuração adotada segue a padronização sugerida pela OIT. Entre os indicadores calculados, a taxa de desocupação é considerada internacionalmente 
como variável proxy da taxa de desemprego. A interrogação que se apresenta em uma comparabilidade mundial diz respeito à interpretação dos resultados dos indicadores de desemprego. Existe uma variedade de classificações sobre os conceitos de indicadores de emprego no país e internacionalmente (Couto; Freitas, 2008; Aguas, 2010).

O IBGE conceitua as pessoas desocupadas como a parcela da População Economicamente Ativa (PEA) que engloba indivíduos sem trabalho na semana de referência, mas que estavam disponíveis para assumir um trabalho nessa semana e que tomaram alguma providência efetiva para conseguir trabalho no período de referência de 30 dias. Dessa forma, a mensuração da taxa de desocupação é expressa pelo percentual de pessoas desocupadas na semana de referência em relação à PEA nessa semana.

Em âmbito mundial, os indicadores são baseados de acordo com as atividades de emprego, definido em concordância com a Classificação Internacional segundo a Situação na Profissão(CISP), aprovada pela Comissão de Estatística das Nações Unidas em 1958 e revista na $15^{\text {a }}$ Conferência Internacional dos Estaticistas do Trabalho (CIET) em 1993. O CISP define seis atividades, que são em grande parte baseadas no tipo de risco econômico associado ao trabalho, um elemento de reforço da conexão entre a pessoa e o emprego, bem como o tipo de autoridade sobre as organizações e sobre os outros trabalhadores de acordo com a posição que têm ou que podem vir a ter: (i) trabalhadores assalariados e remunerados, também conhecidos como empregados; (ii) trabalhadores independentes com empregados, também conhecidos como empregadores; (iii) trabalhadores independentes sem empregados, também conhecidos como trabalhadores por conta própria; (iv) membros das cooperativas de produtores; (v) trabalhadores familiares, também conhecidos como trabalhadores familiares não remunerados; e (vi) trabalhadores não classificados por atividade (ILO, 2009, p. 27).

As discussões mais recentes sobre a metodologia de mensuração de variáveis do mercado de trabalho desenvolvidas no âmbito das conferências da OIT, que fornecem as definições completas de todos os grupos de atividades, foram resumidas em uma publicação (ILO, 2009) que fornece definições, conceitos e fórmulas para cada um dos novos indicadores de emprego. Estes se apresentam como base de mensuração para a adaptação aos Objetivos de Desenvolvimento do Milênio (ODM), estabelecidos pela ONU em 2000, visando "alcançar pleno emprego produtivo e trabalho decente para todos, incluindo mulheres e jovens". A Eurostat, divisão de estatística da Comissão Europeia, corpo executivo da União Europeia e que representa os interesses da EU no contexto mundial, resumindo estas recomendações da OIT, define os desempregados como: 
são todos os indivíduos que não estão empregados durante a semana de referência e procuraram ativamente emprego nas quatro semanas anteriores, isto é, tomaram ações específicas para encontrar trabalho por contra própria ou conta de outrem, estando prontos para começar a trabalhar imediatamente ou nas duas semanas seguintes; inclui também aqueles que têm já um trabalho mas ainda não se encontram a trabalhar e que iniciarão atividade, no máximo, nos três meses seguintes. (CIES, 2010, p. 1).

As definições acima do IBGE de desocupados ("pessoas sem trabalho") e da EUROSTAT de desempregados (“indivíduos que não estão empregados”) são interpretadas nas análises como base para a taxa de desemprego. Esta última definição engloba, portanto, com maior exatidão o volume de desempregados, já que entre as Pessoas Ocupadas (PO) pode se encontrar indivíduos que trabalham, porém em situações não condizentes com o emprego, como será definido em sequência.

As Pessoas Ocupadas (PO) como parcela complementar da População Economicamente Ativa (PEA) são classificadas como as "pessoas que exerceram trabalho, remunerado ou sem remuneração, na semana de referência, durante pelo menos uma hora completa na semana de referência, ou que tinham trabalho remunerado do qual estavam temporariamente afastadas nessa semana" (IBGE, 2007, p. 3). As PO são consideradas como pertencentes a quatro tipos de categorias, de acordo com sua posição na ocupação como: (i) empregado, pessoa que trabalhava para um empregador, geralmente obrigando-se ao cumprimento de uma jornada de trabalho; (ii) conta própria, pessoa que trabalhava explorando o seu próprio empreendimento sozinha ou com sócio, sem ter empregado ou com ajuda de trabalhador não remunerado; (iii) empregador, pessoa que trabalhava explorando o seu próprio empreendimento tendo pelo menos um empregado; (iv) trabalhador não remunerado, pessoa que trabalhava sem remuneração em empreendimento de membros da unidade domiciliar que era conta própria ou empregador (IBGE, 2007).

Nesse sentido, não é possível considerar que todas as pessoas ocupadas por pelo menos uma hora completa na semana de referência estejam empregadas. Tal como definido na Resolução da OIT relativamente às estatísticas da PEA, adotada na $13^{\text {a }}$ Conferência Internacional de Estatísticas do Trabalho (OIT/CIET, 1982), a PEA agrupa as categorias de emprego, subemprego e desemprego. É relevante salientar então a necessidade de interpretar de modo diferenciado os termos trabalho e emprego. Trabalho é considerado como a atividade econômica do trabalhador em ocupação remunerada em dinheiro, ou outros bens ou benefícios (moradia, alimentação etc.) no exercício da produção de bens e serviços ou no serviço doméstico, ou ainda ocupação econômica sem 
remuneração na atividade econômica como membro da unidade domiciliar.

O emprego compreende pessoas acima de um certo nível de idade que trabalharam ou que tiveram um emprego durante um determinado período específico, incluindo pessoas assalariadas (ou com uma remuneração em espécie), pessoas temporariamente ausentes do trabalho por razões tais como doença, maternidade ou paternidade, férias, formação ou conflito industrial, e trabalhadores familiares não assalariados que trabalham pelo menos uma hora (OIT, 1982, 1998).

Além disso, um dos indicadores adotados pela OIT para fornecer a base para avaliar o êxito do pleno emprego produtivo e o trabalho decente no dos ODM, diz respeito à "taxa de emprego em termos do total da população" e se refere à proporção da população ativa que está empregada. O indicador é determinado como o quociente entre o número total de pessoas empregadas acima de uma certa idade (geralmente 15 anos ou mais) pela população ativa da mesma faixa etária. Este indicador geralmente se situa entre os 50 e $75 \%$, sendo que uma taxa mais elevada indica que uma maior proporção da população que deveria estar a trabalhar na realidade está a trabalhar. Uma relação menor indica que uma elevada proporção da população não está envolvida diretamente em atividades relacionadas com o mercado de trabalho. A taxa de emprego em termos do total da população que se situa em proporções acima de $80 \%$ certas vezes ocorre em países muito pobres, o que geralmente indica uma abundância de empregos pouco qualificáveis (ILO, 2009, p. 19).

$\mathrm{O}$ indicador da taxa de emprego em termos do total da população, portanto, mede apenas a quantidade e não faz qualquer referência à qualidade do emprego no qual as pessoas trabalham, e dessa forma não esclarece ao longo do tempo o que representa uma trajetória positiva deste indicador. Um aumento no indicador significa que uma maior percentagem da população no país obteve emprego, o que implicaria na melhora da situação do mercado de trabalho e redução da pobreza apenas se os empregos criados forem bem pagos, produtivos e seguros, ou seja, se forem trabalhos decentes e, dessa forma, não existe uma taxa ótima de emprego em termos do total da população. Como salientam as pesquisas da OIT, as economias desenvolvidas tendem a ter proporções menores de crescimento da taxa do que os países em desenvolvimento, sendo que uma maior produtividade e rendimento significam que poucos trabalhadores são necessários para reunir as necessidades de toda a população. Por outro lado, um aumento da taxa em proporções muito elevadas pode indicar que a maioria das pessoas pobres não está trabalhando de acordo com as necessidades de subsistência independentemente da qualidade do trabalho (ILO, 2009, p. 21).

Ainda de acordo com Resolução da OIT na $16^{\text {a }}$ Conferência Internacional dos Estaticistas do Trabalho (1998), consideram-se como subocupadas as pessoas 
que, na semana de referência, trabalharam efetivamente menos que uma determinada jornada de trabalho fixada de acordo com as circunstâncias nacionais, desejavam trabalhar mais e estavam disponíveis para tal.

Por sua vez, entre as pessoas ocupadas são registradas algumas categorias de pessoas segundo sua posição na ocupação: empregado, conta própria, empregador e trabalhador não remunerado.

(i) Empregado, se refere a pessoa que trabalhava para um empregador, pessoa física ou jurídica, cumprindo uma jornada de trabalho e recebendo em contrapartida uma remuneração em dinheiro, mercadorias, produtos ou benefícios, incluindo-se nesta categoria a pessoa que presta serviço militar obrigatório, o clérigo e também o aprendiz ou estagiário que recebe somente aprendizado ou treinamento como pagamento, o trabalhador doméstico e ainda o trabalhador não remunerado de membro da unidade domiciliar que era empregado (IBGE, 2007). Dessa forma, as pessoas ocupadas que na semana de referência exerciam trabalho em um período inferior a uma jornada de trabalho e que estavam disponíveis para assumir emprego nessa semana e tomaram alguma providência efetiva para conseguir trabalho no período de referência de 30 dias, não devem ser consideradas como empregados, apesar de exercerem algum trabalho;

(ii) Conta própria, define o indivíduo que trabalha explorando o seu próprio empreendimento, sozinho ou com sócio, sem ter empregado e contando, ou não, com ajuda de trabalhador não remunerado de membro da unidade domiciliar;

(iii) Empregador, representado por pessoa que trabalha explorando o seu próprio empreendimento, tendo pelo menos um empregado e contando, ou não, com ajuda de trabalhador não remunerado de membro da unidade domiciliar;

(iv) Trabalhador não remunerado de membro da unidade domiciliar, consiste em conta própria ou empregador, que trabalha sem remuneração em empreendimento de membro da unidade domiciliar que é conta própria ou empregador. 
A partir destas conceituações, é possível questionar se, uma vez que existe o empregado, a condição oposta a esta situação deve ser considerada de desempregado, ou seja, indivíduos que embora ocupados, não trabalhavam para um empregador (pessoa física ou jurídica) cumprindo uma jornada de trabalho e recebendo em contrapartida uma remuneração em dinheiro, mercadorias, produtos ou benefícios. As metodologias da OIT e do IBGE se referem explicitamente a esta categoria de pessoas ocupadas na semana de referência, que procuraram trabalho no período de 30 dias, mas que estavam disponíveis para assumir um outro trabalho ou trabalho adicional nessa semana e, no período, tomaram alguma providência efetiva para conseguir trabalho distinto do(s) que tinha(m) nesse período. Nesta condição, apesar de estar ocupada em trabalho remunerado por mais de uma hora na semana de referência, o trabalhador declara que não se encontra satisfatoriamente empregado e remunerado (IBGE, 2007; ILO, 2009).

Os conceitos propostos pela OIT definem ainda dois outros indicadores que mensuram situações em que podem se encontrar o empregado:

(i) "Taxa de trabalhadores na pobreza", conceito que se refere a trabalhadores que vivem num agregado cujo os membros estima-se que vivam abaixo do nível nacional definido de pobreza. O número de trabalhadores na pobreza pode ser calculado através da equação:

Taxa de trabalhadores na pobreza $=$ (número de trabalhadores que vivem num agregado familiar com um rendimento abaixo do nível de pobreza/total de emprego) $x$ 100. (ILO, 2009, p. 23).

A hipótese-chave sobre este indicador é que quase todos os pobres que fazem parte do mercado de trabalho estão empregados e esta suposição é feita porque em países em que não existem poupanças sociais, os indivíduos na pobreza devem trabalhar no sentido de manter um nível de subsistência.

(ii) "Taxa de emprego vulnerável", que indica uma medida daquilo que são consideradas as atividades de emprego mais vulneráveis, ou seja, trabalhadores por conta própria e trabalhadores familiares. Esta taxa é calculada como a soma de trabalhadores por conta própria e de trabalhadores 
familiares como uma proporção do total de emprego:

Taxa de emprego vulnerável $=[$ (número de trabalhadores por conta própria + número de trabalhadores familiares) $x$ total de emprego]/100. (ILO, 2009, p. 27).

Os indicadores acima definem os indivíduos que compõem a PEA, e com relação a este grupo de pessoas é necessário salientar duas outras condições de pessoas que no momento da mensuração estão incluídas na População Não Economicamente Ativa e não na PEA, porém que potencialmente poderiam estar ativos, o que muda consideravelmente a base de cálculo dos indicadores mencionados. Referem-se a:

(i) "Pessoas marginalmente ligadas à população economicamente ativa" na semana de referência, definidas como as pessoas não economicamente ativas que trabalharam ou procuraram trabalho no período de referência de 365 dias e estavam disponíveis para assumir um trabalho na semana de referência; e

(ii) "Pessoas desalentadas", definidas como as pessoas marginalmente ligadas à população economicamente ativa na semana de referência da pesquisa. que procuraram trabalho ininterruptamente durante pelo menos seis meses, contados até a data da última providência tomada para conseguir trabalho no período de referência de 365 dias, tendo desistido por não encontrar qualquer tipo de trabalho, trabalho com remuneração adequada ou trabalho de acordo com as suas qualificações.

Portanto, é pertinente investigar a interpretação devida dos indicadores calculados pois, se de um lado, é exigida precisão em sua mensuração, por outro deve garantir-se que as análises neles baseadas identifiquem a real situação da qualidade do mercado de trabalho que em termos quantitativos parece se aproximar de uma situação de pleno emprego. Nesta interpretação pode ocorrer a possibilidade de se tomarem como base várias taxas de desemprego (por exemplo, incluindo os desencorajados ou o subemprego visível) que não estão corretamente calculadas, na medida em que, ao estabelecer-se como base de análise uma determinada taxa de desemprego (população desempregada/PEA), 
esta deve ser submetida aos ajustamentos necessários em função das possíveis diferenças no conceito de desemprego (numerador), o que significa que essa alteração deveria se refletir necessariamente na população ativa (denominador).

\section{A interpretação do pleno emprego no Brasil: desemprego ou desocupação?}

Como definido, o pleno emprego, em economia, tem como base uma situação em que não existe qualquer forma de desperdício, seja do capital ou do trabalho, ou seja, significa a utilização da capacidade máxima de produção de uma sociedade e, evidentemente, deve ser utilizada para elevar a qualidade de vida da população. No entanto, como salientado pela OIT, o pleno emprego precisa vir acompanhado de trabalho decente.

A definição de pleno emprego pode variar de um país para outro. Mas, em termos empíricos, o emprego máximo significaria zero desemprego? A OIT considera que ele é estabelecido quando as taxas de desocupados ficam abaixo de $3 \%$, índices registrados nos países desenvolvidos no período após a Segunda Guerra Mundial. Como observado anteriormente, no mês de dezembro de 2011 foi registrado o nível de desocupação no Brasil de 4,7\%, considerado próximo ao pleno emprego, e em maio de 2012 a OIT-Brasil divulgou os dados da Tabela 1, que mostram que o país passou a apresentar um nível de desemprego inferior a média mundial e a média dos países desenvolvidos após a crise financeira mundial de 2008.

Tabela 1 - Taxas de desemprego no Brasil, mundo e países desenvolvidos (\%)

\begin{tabular}{l|r|r|r}
\hline & $\mathbf{2 0 0 7}(*)$ & $\mathbf{2 0 1 0}$ & $\mathbf{2 0 1 2 ( * * )}$ \\
\hline Brasil & 8,2 & 5,7 & 6,0 \\
Mundo & 5,6 & 6,2 & 6,2 \\
Países desenvolvidos & 5,8 & 8,8 & 8,5 \\
\hline
\end{tabular}

Nota: (*) Antes da crise de 2008; (**) Abril/2012.

Fonte: ILO (2012).

Os debates questionam se a situação brasileira está caminhando para o pleno emprego e se, em relação aos demais países, o mercado de trabalho do país se encontra melhor situado do que a média dos demais. A resposta positiva para estas duas questões encobre a real condição de trabalho no Brasil, que pode ser melhor visualizada a partir da investigação sobre a distribuição da população ocupada, segundo categorias específicas de trabalho.

A primeira questão que se coloca é o fato de que a PME, que é uma pesquisa domiciliar de periodicidade mensal, investiga características da população residente na área urbana das regiões metropolitanas de abrangência, atualmente abrangendo as Regiões Metropolitanas de Recife, Salvador, Belo 
Horizonte, Rio de Janeiro, São Paulo e Porto Alegre. Além do mais, a Pesquisa Mensal de Emprego é realizada por meio de uma amostra probabilística, planejada de forma a garantir a representatividade dos resultados para os níveis geográficos em que a pesquisa é produzida (IBGE, 2007). Análises regionais no país (Kon, 2002) destacam as diversidades consideráveis entre as estruturas ocupacionais nas metrópoles e no resto das regiões das Unidades Federativas (UF's) e entre as UF's. Dessa forma, a taxa de 6\% da tabela se refere apenas às principais metrópoles do país. Qual seria a taxa de ocupação fora das metrópoles, no interior de cada estado?

Uma comparação de indicadores de trabalho entre a PME e a Pesquisa Nacional por Amostra de Domicílios (PNAD), realizada anualmente a partir de uma amostra para o país como um todo, é apresentada na Tabela 2. É possível verificar-se a considerável diferença nos vários indicadores e particularmente nas taxas de desocupação, quando a amostra abrange apenas algumas regiões metropolitanas $(7,7 \%)$ ou o país como um todo $(3,6 \%)$.

Tabela 2 - Indicadores de trabalho em setembro/2009 - Brasil

\begin{tabular}{l|r|r}
\hline & \multicolumn{1}{c|}{ PME } & \multicolumn{1}{c}{ PNAD } \\
\hline População em Idade Ativa - PIA (Milhões) & 41,0 & 162,8 \\
População Economicamente Ativa - PEA (Milhões) & 23,3 & 96,2 \\
Taxa de atividade (PEA/PIA) (\%) & 56,8 & 62,1 \\
População Ocupada - PO (Milhões) & 21,5 & 96,4 \\
PO - com carteira (\%) & 45,0 & 33,9 \\
Taxa de desocupação (\%) & 7,7 & 3,6 \\
Empregados/PEA (\%) & $\ldots$ & 56,5 \\
Nivel de ocupação (\%) & 52,4 & 56,9 \\
\hline
\end{tabular}

Fonte: IBGE - PME/2009 e PNAD/2009.

No entanto, a PNAD apresenta um dado relevante que não é calculado na PME, que pode dar uma dimensão a mais na análise do real parâmetro do desemprego: a participação dos empregados na PEA correspondia a 56,5\%. A distribuição destes empregados compreende $60 \%$ de ocupados com carteira de trabalho, $28,2 \%$ sem vínculo empregatício e $12 \%$ de militares e estatutários. A PNAD 2009 mostra ainda características de subemprego no Brasil, desde que $5,8 \%$ dos ocupados trabalhavam até 14 horas por semana e $22 \%$ de 15 a 39 horas, ou seja, por períodos inferiores à jornada legal de trabalho.

Dados mais recentes mostram que a taxa de ocupação da PME, como o complemento da Taxa de Desocupação (TD) na PEA, em abril de 2012 correspondia a $94 \%$, incorporando trabalhadores que se encontram em situações de subemprego, pessoas que não mantem vínculo legalizado com um empregador, pessoas que trabalham por conta própria em condições de trabalho que podem ser satisfatórias, mas também podem ser precárias e não protegidas; dessa forma, está longe de ser aproximada à taxa de emprego, ou seja, o percentual de trabalhadores da PEA que se encontram na situação de empregados, desde 
que trabalhavam para um empregador. O nível de informalidade, embora decrescente, ainda ficou em 34,3\% dos trabalhadores em janeiro de 2012.

A pesquisa sobre emprego do Dieese/Seade ${ }^{1}$ (Tabela 3), embora também abranja apenas regiões metropolitanas, parte de conceitos diferenciados de desemprego, que levam em conta trabalhos precários e desalento, considerando:

(i) Taxa de desemprego - proporção da PEA que se encontra na situação de desemprego total (aberto mais oculto);

(ii) Desemprego oculto:

(a) pessoas que realizam trabalhos precários (algum trabalho remunerado ocasional de auto-ocupação) ou não remunerado e que procuraram mudar de trabalho nos 30 dias anteriores à semana de referência ou sem êxito nos 12 meses anteriores;

(b) Oculto pelo desalento - pessoas que não possuem trabalho nem procuraram nos últimos 30 dias anteriores por desestímulos do mercado de trabalho, mas apresentaram procura efetiva de trabalho nos últimos 12 meses.

Tabela 3 - Taxas de desemprego nas regiões metropolitanas $\left(^{*}\right)(\%)$

\begin{tabular}{lr|r|r|r|r|r}
\hline \multicolumn{1}{c}{ Taxas de desemprego } & $\mathbf{1 9 9 8}$ & $\mathbf{2 0 0 5}$ & $\mathbf{2 0 0 6}$ & $\mathbf{2 0 0 9}$ & $\mathbf{2 0 1 0}$ & $\mathbf{2 0 1 1}$ \\
\hline Total & 18,7 & 17,9 & 16,8 & 14 & 11,9 & 10,5 \\
Aberto & 11,7 & 11,3 & 11 & 9,7 & 8,5 & 7,9 \\
Oculto & 6,9 & 6,6 & 5,7 & 4,3 & 3,4 & 2,6 \\
Trabalho precário & 4,6 & 4,6 & 3,9 & 2,8 & 2,3 & 1,7 \\
Desalento & 2,3 & 2,1 & 1,9 & 1,5 & 1,1 & 0,9 \\
\hline
\end{tabular}

Fonte: Dieese - Convênio Seade-Dieese, MET/FAT e convênios regionais.

Nota: $\left(^{*}\right)$ Correspondem ao total das regiões metropolitanas de Belo

Horizonte, Porto Alegre, Recife, Salvador, São Paulo e Distrito Federal.

Observe-se inicialmente na Tabela 3 que a taxa de desemprego total foi de 14\% em 2009, quando as informações de taxa de ocupação do mesmo ano pela PME e pela PNAD se situaram respectivamente em 7,7\% e 3,3\%, desde que não incluíam o desemprego oculto e o subemprego. Dessa maneira, é possível inferirse que as taxas de desemprego Dieese/Seade estão mais próximas à realidade do mercado de trabalho brasileiro. Por outro lado, é verificado que as taxas de desemprego de todos os tipos da pesquisa Dieese decresceram gradativamente no período analisado, porém o desemprego oculto ainda permaneceu em quase $3 \%$ em 2011.

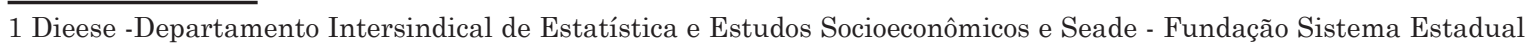
de Análise de Dados. 


\section{Considerações finais}

As conceituações teóricas sobre o pleno emprego implicam, no caso da oferta de mão de obra, o desenvolvimento das potencialidades da população ativa e, do lado da procura de trabalhadores, a capacidade de criação de emprego em números e nas qualificações suficientes e em condições adequadas à oferta, sem comprometer, contudo, a produtividade do trabalho.

Nesse sentido, a economia brasileira se encontra afastada do pleno emprego, desde que apresenta características específicas da estruturação do mercado de trabalho, marcadas por um mercado informal grande, subocupação, baixos salários ${ }^{2}$ e rendimentos médios baixos que não condizem com uma situação de pleno emprego.

A pesquisa base para a determinação do desemprego no país oculta esta real situação da qualidade do trabalho e dificulta as análises conjunturais que servem de base para o entendimento da situação do país no contexto mundial, particularmente em momentos de crise econômica, e pode viesar a elaboração de políticas públicas e privadas voltadas para a modernização do mercado de trabalho. A reformulação da mensuração do indicador de desemprego deve ser elaborada de modo a incorporar a parcela dos trabalhadores que se encontram em situações precárias de trabalho ou situações em que o potencial de produtividade do trabalho não está completamente utilizado. Estas reformulações dizem respeito ainda à determinação de uma amostra representativa do país como um todo, e que apresente as diferenças regionais consideráveis da estrutura ocupacional.

Assim, o problema de definir, ou interpretar o significado do estado de pleno emprego em uma economia significa também entender o nível de intervenção governamental possível e necessária através de políticas públicas para manter aquele estado. A utilização de um indicador específico para a análise do mercado de trabalho pode ocultar o verdadeiro diagnóstico da situação brasileira, dificultando a formulação das políticas necessárias de apoio a este mercado e à força de trabalho.

\section{Referências}

Aguas, M. F. F. (2010). "Uma análise da evolução recente da Taxa de Desemprego segundo diferentes classificações". Encontro ABEP/NEPO.

CIES. (2010). "Observatório das desigualdades: indicadores de desemprego Eurostat". URL [on-line]: http://observatorio-das-desigualdades.cies.iscte.pt/index.jsp.

Couto, J. M.; Couto, A. C. L.; Freitas, C. E. (2008). "PIB, desemprego e Keynes:

2 Segundo o IPEA, 80\% dos salários se situam em até dois salários mínimos. 
relações concretas (1991-2008)". A Economia em Revista 16(1).

IBGE. (2007). "Notas metodológicas, em Pesquisa Mensal de Emprego". Série Relatórios Metodológicos 23. URL [on-line]: http://www.ibge.gov.br/home/ estatistica/. Acesso em: 02 de abril de 2012.

IBGE. (2012). Pesquisa Mensal de Emprego. URL [on-line]: http://www.ibge.gov.br/ home/estatistica/. Acesso em: 02 de abril de 2012.

IBGE. (2009). Pesquisa Nacional por Amostra de domicílios - 2009, vol. 30. Rio de Janeiro: IBGE.

ILO. (2007). "Director-General's introduction to the International Labour Conference decent work for sustainable development". ILC 96-2007/Report I (A).

ILO. (2012). Global Employment Trends 2012. Geneva: ILO. URL [on-line]: http:www. oit.org.br. Acesso em: 30 de maio de 2012.

ILO. (2009). Guide to the new Millennium Development Goals Employment Indicators: including the full set of decent work indicators. Geneva: ILO.

Keynes, J. M. (1983). Teoria geral do emprego, do juro e da moeda. São Paulo: Abril cultural.

Kon, A. (Org.) (2002). Unidade e fragmentação: a questão regional no Brasil. São Paulo: Perspectiva.

Missio, F. J.; Oreiro, J. L. (2006). "Equilíbrio com pleno emprego e equilíbrio com desemprego em um contexto de preços e salários flexíveis: o debate entre Keynes e os (neo) clássicos". Texto para discussão Revista Economia \& Tecnologia. URL [on-line]: http://www.economiaetecnologia.ufpr.br/textos_discussao/texto_para_ discussao_ano_2006_texto_05.pdf.

OIT. (2007). Trabalho decente e juventude - América Latina. Brasília: OIT Brasil.

OIT. (1998). Décima Sexta Conferência Internacional dos Estaticistas do Trabalho, Genebra: OIT..

OIT/CIET. (1982). Décima Terceira Conferência Internacional dos Estaticistas do Trabalho, Genebra: OIT/CIET.

OIT. (2009). Guia sobre os novos indicadores de ermprego dos Objetivos de Desenvolvimento do Milênio. Genebra: OIT.

Pigou, A. C. (1968). The theory of unemployment. New York: Augustus M. Kelley. 
